\title{
Optimal insulin regimens in type 2 diabetes mellitus: systematic review and meta-analyses
}

\author{
D. S. Lasserson • P. Glasziou • R. Perera • \\ R. R. Holman • A. J. Farmer
}

Received: 25 March 2009/Accepted: 15 June 2009 /Published online: 31 July 2009

(C) Springer-Verlag 2009

\begin{abstract}
Aims/hypothesis We compared the effect of biphasic, basal or prandial insulin regimens on glucose control, clinical outcomes and adverse events in people with type 2 diabetes.

Methods We searched the Cochrane Library, MEDLINE, EMBASE and major American and European conference abstracts for randomised controlled trials up to October 2008. A systematic review and meta-analyses were performed.

Results Twenty-two trials that randomised 4,379 patients were included. Seven trials reported both starting insulin dose and titration schedules. Hypoglycaemia definitions and glucose targets varied. Meta-analyses were performed pooling data from insulin-naive patients. Greater $\mathrm{HbA}_{1 \mathrm{c}}$ reductions were seen with biphasic and prandial insulin, compared with basal insulin, of $0.45 \%$ (95\% CI $0.19-0.70$, $p=0.0006)$ and $0.45 \%$ (95\% CI $0.16-0.73, p=0.002$ ), respectively, but with lesser reductions of fasting glucose of $0.93 \mathrm{mmol} / 1 \quad(95 \%$ CI $0.21-1.65, p=0.01)$ and $2.20 \mathrm{mmol} / 1$ (95\% CI 1.70-2.70, $p<0.00001)$, respectively. Larger insulin doses at study end were reported in biphasic and prandial arms compared with basal arms. No studies found differences in major hypoglycaemic events, but minor hypoglycaemic events for prandial and biphasic
\end{abstract}

D. S. Lasserson $(\bowtie) \cdot$ P. Glasziou $\cdot$ R. Perera $\cdot$ A. J. Farmer

Division of Public Health and Primary Care,

University of Oxford,

Rosemary Rue Building, Old Road Campus, Headington, Oxford OX3 7LF, UK

e-mail: daniel.lasserson@dphpc.ox.ac.uk

R. R. Holman

Diabetes Trials Unit, Oxford Centre for Diabetes,

Endocrinology and Metabolism, University of Oxford,

Oxford, UK insulin were inconsistently reported as either higher than or equivalent to basal insulin. Greater weight gain was seen with prandial compared with basal insulin $(1.86 \mathrm{~kg}, 95 \%$ CI 0.80-2.92, $p=0.0006$ ).

Conclusions/interpretation Greater $\mathrm{HbA}_{1 \mathrm{c}}$ reduction may be obtained in type 2 diabetes when insulin is initiated using biphasic or prandial insulin rather than a basal regimen, but with an unquantified risk of hypoglycaemia. Studies with longer follow-up are required to determine the clinical relevance of this finding.

Keywords Insulin · Meta-analysis · Systematic review · Type 2 diabetes
Abbreviations
OHA Oral hypoglycaemic agent
PPG Postprandial glucose
RCT Randomised controlled trial
SMBG Self-monitored blood glucose

\section{Introduction}

Type 2 diabetes is a progressive disease [1] and its prevalence is projected to increase [2]. The optimal glycaemic treatment strategy is uncertain, but intensifying glucose control reduces microvascular complication rates [3-5] and the risk of macrovascular disease [4-8]. Initiating insulin therapy is recommended when diet and oral hypoglycaemic agents (OHAs) fail to maintain an $\mathrm{HbA}_{1 \mathrm{c}}<7 \%[9,10]$ and the majority of patients become insulin-requiring over time by this criterion [11]. However, most patients in Europe and America have inadequate glucose control $[12,13]$, reflecting in part delays in initiating insulin therapy [14]. 
The choice of an initial insulin regimen for people with type 2 diabetes varies among clinicians with biphasic, short-acting and intermediate or long-acting insulin formulations being used. Whichever is chosen, starting insulin alongside rather than instead of OHAs improves glycaemic control and reduces the required daily insulin dose $[11,15,16]$.

Biphasic insulin accounts for the majority of insulin prescriptions, as worldwide figures show greater consumption of biphasic insulin than either short- or long-acting insulin [17]. There is, however, no conclusive evidence base to support the predominance of a biphasic regimen. Recent reviews have focused on comparing biphasic conventional with biphasic analogue insulins rather than on assessing the superiority of a biphasic regimen $[15,18]$.

In the UK the National Institute for Health and Clinical Excellence reviewed insulin efficacy data at initiation (although without considering short-acting insulin) and recommended basal over biphasic insulin, unless $\mathrm{HbA}_{1 \mathrm{c}}$ was $>9.0 \%$ [19]. Clinical practice recommendations from reviews based on selected rather than systematically appraised evidence suggest that basal or biphasic regimens be used once daily at initiation $[9,20,21]$. These recommendations are based on three perceived advantages: the approach is simple; there are possible benefits of supporting remaining pancreatic beta cell function in early disease; and the level of $\mathrm{HbA}_{1 \mathrm{c}}$ may be reduced by targeting fasting glucose [22]. However, the physiological profile of prandial insulin, either alone or with basal insulin also has theoretical advantages but is not widely used as an initial regimen.

Published analyses of randomised controlled trials (RCTs) have focused on comparing analogue with conventional insulin in the same regimen [23] or on comparing insulin with and without OHAs [15]. The clinician's choice of regimen would be guided more accurately if the comparative effects on both glycaemic control and rate of side effects were known. We performed this systematic review to assess the efficacy and acceptability of the common choices of insulin regimen, with or without OHA continuation.

\section{Methods}

Inclusion and exclusion criteria Trials were included in the review if they compared different insulin regimens using basal, prandial or biphasic insulin formulations and recruited patients $>18$ years old with a diagnosis of type 2 diabetes as defined by criteria current at the time of the trial $[24,25]$. Trials were rejected if (1) the use of OHAs was unbalanced across study arms, (2) the intervention time was $<3$ months, or (3) comparisons were between analogue and conventional insulin within the same regimen. Data were collected on outcomes of mortality, morbidity, glycaemic control $\left(\mathrm{HbA}_{1 \mathrm{c}}\right)$, fasting glucose, postprandial glucose (PPG), weight gain, hypoglycaemic event rate and quality-of-life measurements.

Search strategy The Cochrane Controlled Trials Registry (third quarter 2008), MEDLINE (1966 to October 2008) and EMBASE (1980 to October 2008) were searched using the Cochrane Collaboration Endocrine and Metabolic Disorders Group strategy for type 2 diabetes and RCTs [26], plus terms to identify trials using long-acting, shortacting and biphasic insulins. Reference lists of identified trials and relevant reviews were searched. Abstracts of international diabetes meetings were hand-searched to identify unpublished relevant trials. Registered trial lists were searched for unpublished data (Current Controlled Trials [www.controlled-trials.com]; UK National Research Register [www.update-software.com/National]; and National Institutes of Health [http://clinicalstudies.info.nih.gov]; accessed 1 October 2008).

Data extraction and study quality Two reviewers (D. S. Lasserson and A. J. Farmer) identified relevant publications and abstracted the data, and any disagreements were resolved by consensus and discussion with a third reviewer (P. Glasziou). Methodological quality was scored using criteria set out by Jadad et al. [27] with an additional point given if the analysis was by intention-to-treat.

Statistical methods Data were analysed according to the Cochrane Handbook for Systematic Reviews of Interventions 4.2.5 [28] using Review Manager (Version 4.2.7; Update Software, Oxford, UK). The mean change in the outcome variables over the study period was recorded from tables or figures (SDs if unavailable were imputed using either a correlation of 0.5 , or one calculated from studies where such data were reported).

Data from patients with similar pre-study insulin exposure were pooled in meta-analyses for all available outcomes, to allow for generalisation of results to patients either starting insulin or switching insulin regimens. The inverse variance method was used to calculate an overall effect (weighted mean difference) for each comparison of insulin regimens. For crossover studies only first-period data were included where available unless within-person differences with appropriate measures of dispersion were quoted or could be estimated from test statistics [29]. Data from three-arm trials were pooled such that each group only appeared once in any meta-analysis. If significant heterogeneity was present at $p=0.1$ [28] the meta-analysis was repeated using a random-effects model [30] and potential sources were explored with analysis of subgroups [31-33], 
which were pre-specified as OHA use, insulin type (analogue, conventional), quality score $(<3, \geq 3)$, titration reporting, fasting glucose target $(<7, \geq 7 \mathrm{mmol} / \mathrm{l})$ and baseline glycaemic control $(<9 \%, \geq 9 \%)$.

Funnel plots and a simple graphical test were used to look for evidence of small study and publication bias [34].

\section{Results}

\section{Description of studies}

Figure 1 shows the flow diagram of studies [35]. The majority of references screened did not identify potentially relevant trial reports. Twenty-two trials, which randomised a total of 4,379 patients, met the inclusion criteria. The characteristics of these patients and the insulin regimens examined are shown in Table 1. Scores of methodological quality were generally low (median score $=3$, range 2-5). Nine trials fully described the randomisation process. One trial had patients and care providers blinded to allocation, and 12 had a clear intention-to-treat analysis.

Reports of the interventions showed variable detail (Table 1). Twenty-one trials reported fasting glucose targets (median 7.0, range $6.1-8.9 \mathrm{mmol} / \mathrm{l})$. Thirteen trials reported PPG targets (median 10, range 7-10 mmol/l). Eleven trials reported data on insulin starting doses and eight trials reported titration steps ranging from 2 units to $20 \%$ of daily dose. Definitions of hypoglycaemia, where reported, also varied (Table 1).

Biphasic vs basal insulin

Ten trials recruited a total of 2,160 patients with a median follow-up period of 5 months (range 3-12 months).

$H b A_{1 c}$ Pooling five trials that presented appropriate data and recruited insulin-naive patients [36-40], showed that, compared with basal insulin, biphasic insulin reduced $\mathrm{HbA}_{1 \mathrm{c}}$ by a further $0.45 \%$ (95\% CI $0.19-0.70, p=0.0006)$, but this varied considerably between studies $\left(I^{2}=66.1 \%\right)$ (Fig. 2a). Heterogeneity was not explained by OHA use, reporting insulin titration or baseline diabetic control. Three trials, which did not quote measures of dispersion [41-43], showed either a small $\mathrm{HbA}_{1 \mathrm{c}}$ reduction in favour of biphasic or no significant difference. Two trials [44, 45], which recruited patients already using insulin, showed greater reductions with biphasic insulin $(0.5 \%$ and $0.4 \%$, respectively). Eight trials reported either mean or median final insulin doses with all trials reporting larger amounts for biphasic than basal insulin.
Fig. 1 Systematic review flow diagram. $n=$ number of trial reports
Unique references identified from database searches $(n=3,625)$

References identified from conference abstracts $(n=4)$

Trials to assess for potential inclusion in review $(n=79)$

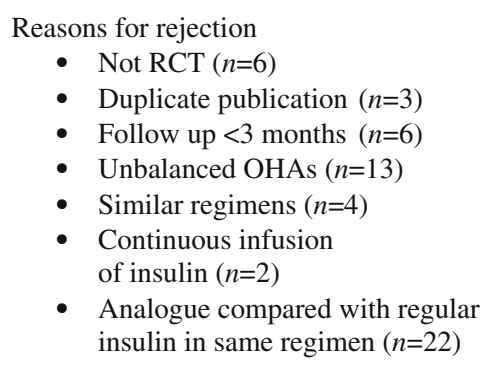

- Follow up $<3$ months $(n=6)$

- Unbalanced OHAs $(n=13)$

- Similar regimens $(n=4)$

- Continuous infusion of insulin ( $n=2)$

- Analogue compared with regular insulin in same regimen $(n=22)$

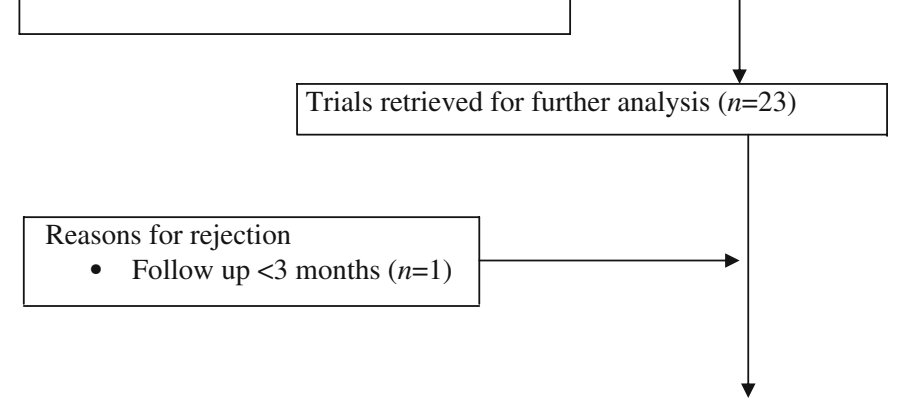

Trials included in review $(n=22)$ (total of 4,379 patients) 


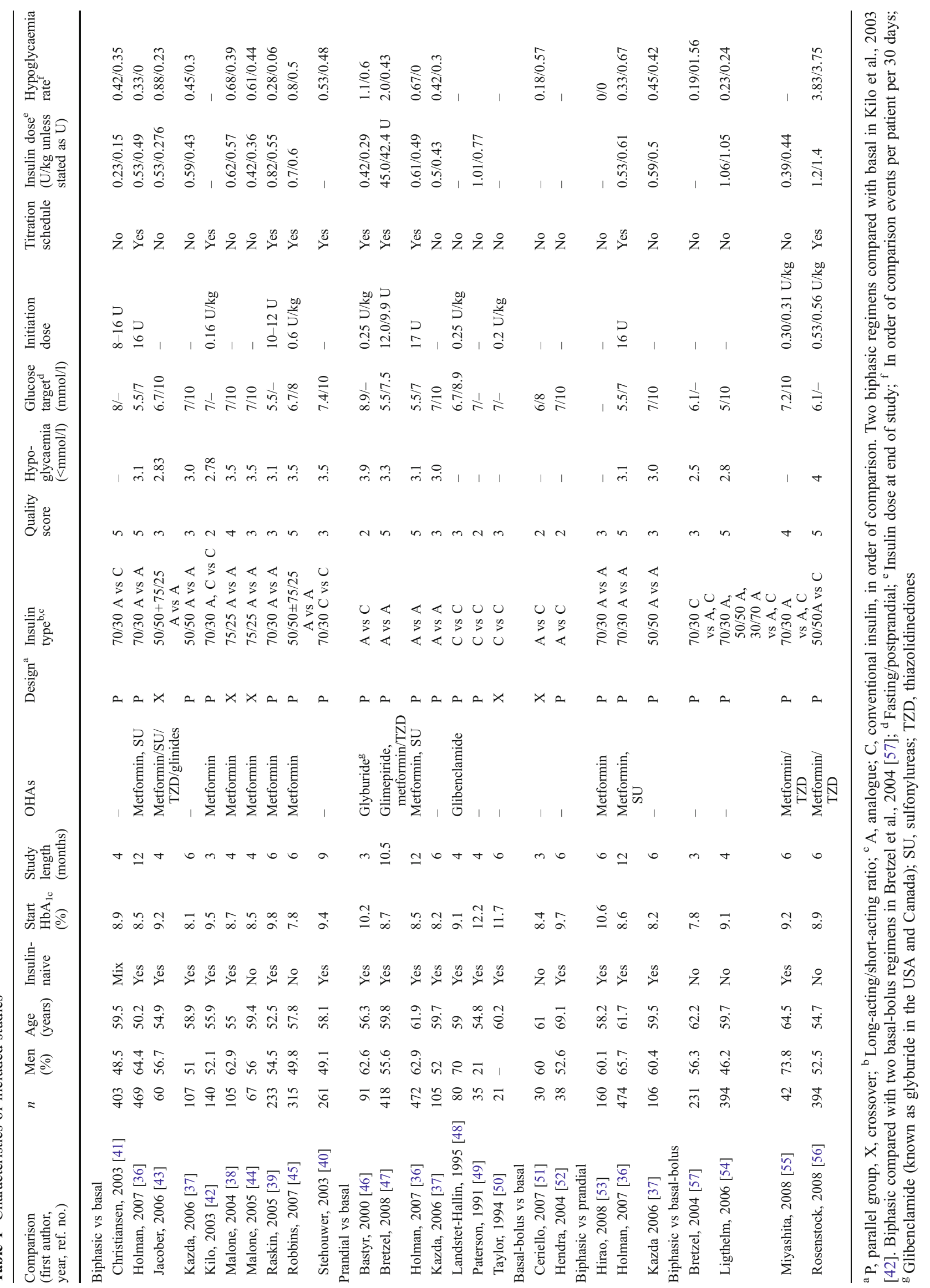


a

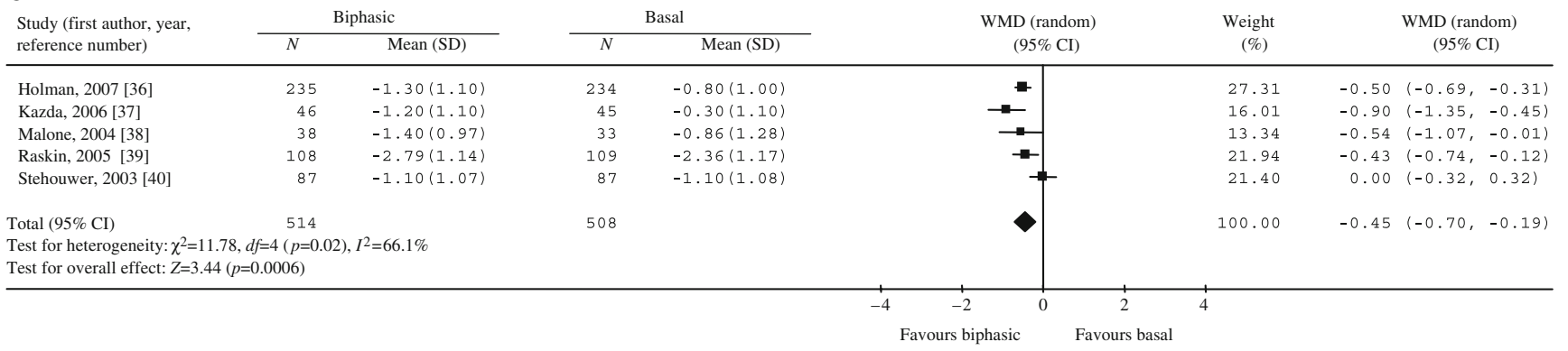

b

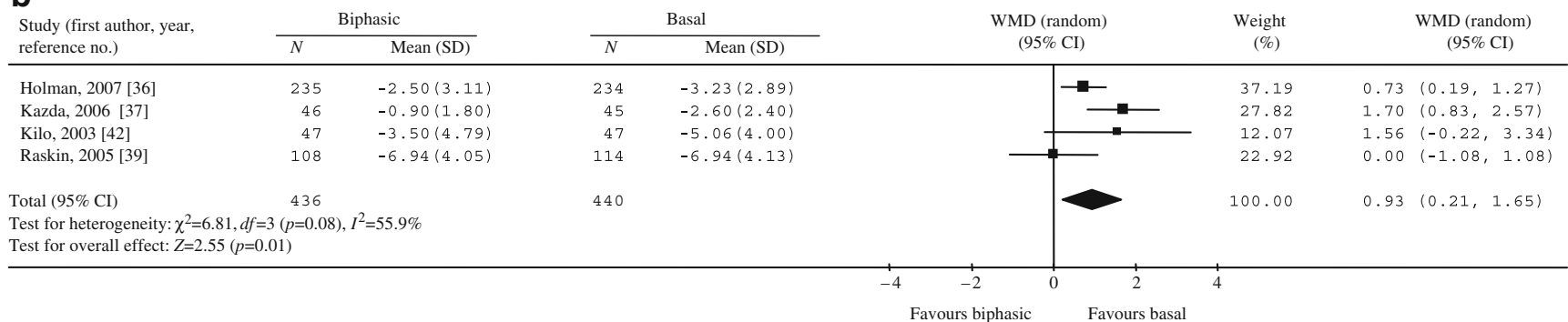

\section{C}

Study (first author, year, reference number)

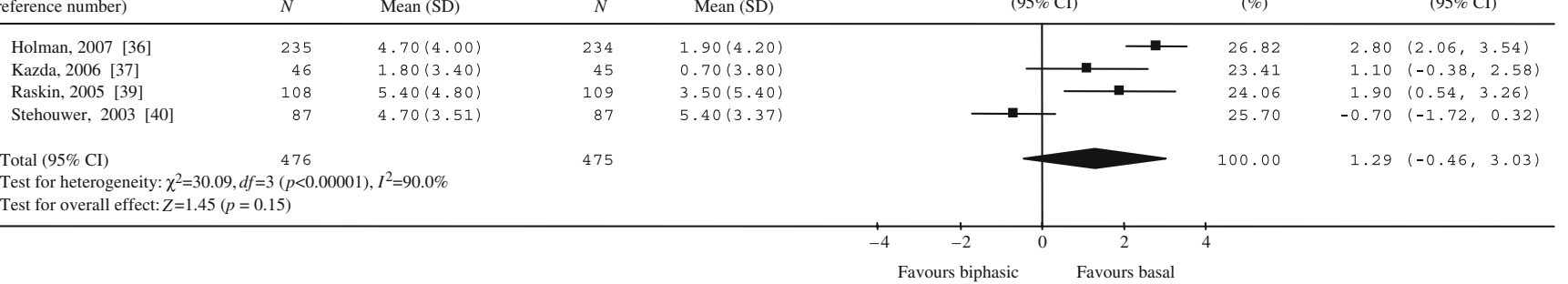

d

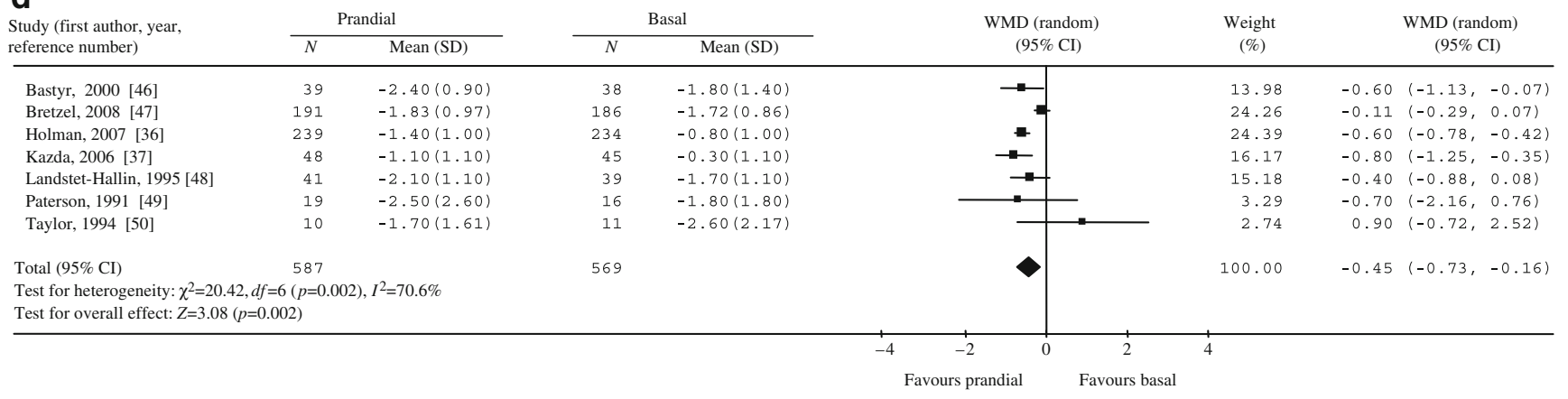

e

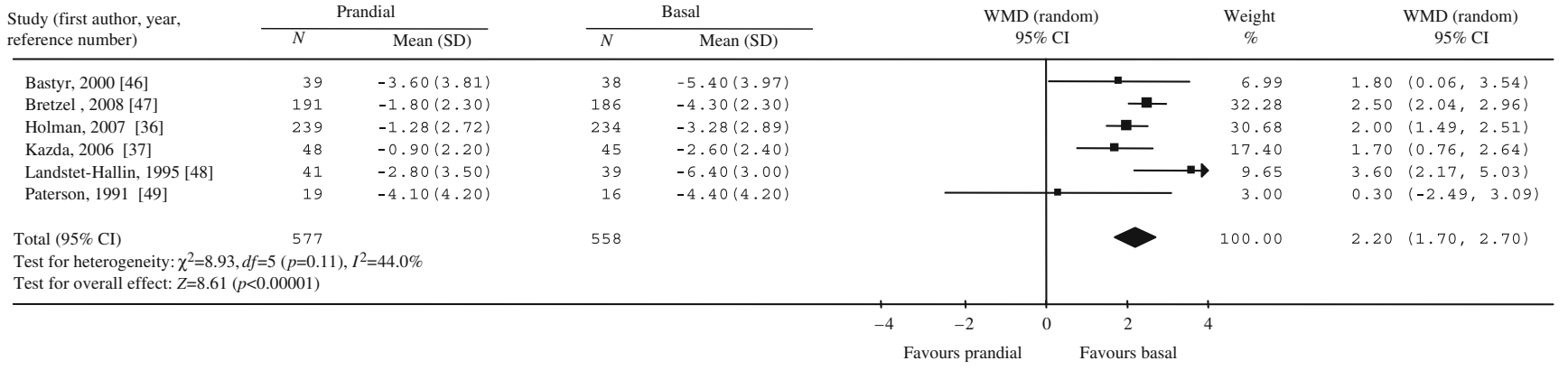

Fig. 2 a-c Biphasic vs basal. Outcome, change in $\mathrm{HbA}_{1 \mathrm{c}}(\%)(\mathbf{a})$, in fasting SMBG (mmol/l) (b) and in weight (kg) (c). d-f Prandial vs basal. Outcome, change in $\mathrm{HbA}_{1 \mathrm{c}}(\%)(\mathbf{d})$, in fasting SMBG (mmol/l) (e) and in weight $(\mathrm{kg})(\mathbf{f})$. WMD, weighted mean difference 
f

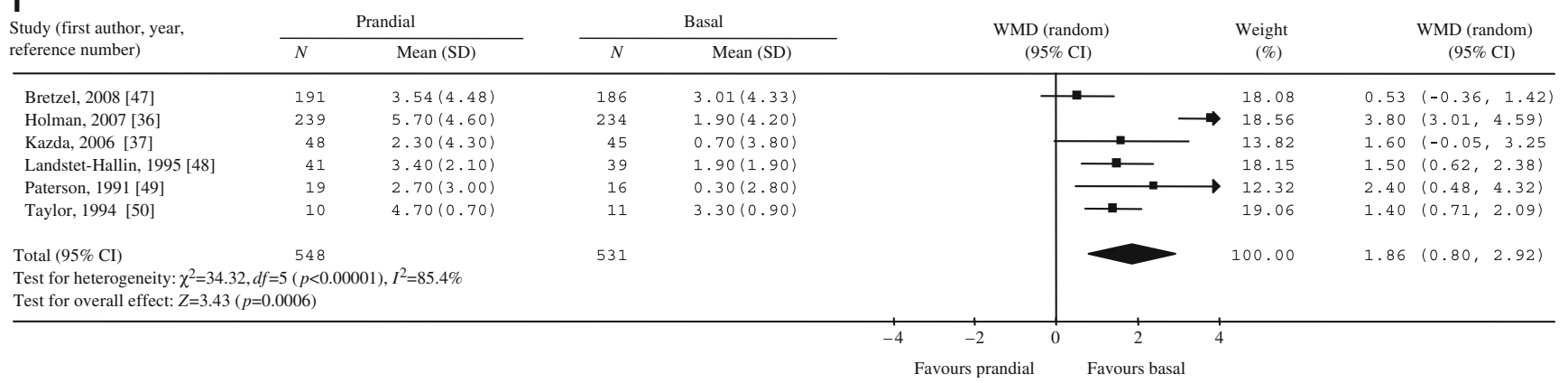

Fig. 2 (continued)

Fasting glucose Pooling four trials that recruited insulinnaive patients [36, 37, 39, 42] showed that, compared with biphasic insulin, basal insulin reduced fasting selfmonitored blood glucose (SMBG) by a further $0.93 \mathrm{mmol} / 1(95 \%$ CI $0.21-1.65, p=0.01)$ but with high heterogeneity $\left(I^{2}=55.9 \%\right)$ (Fig. $\left.2 b\right)$. Heterogeneity was not explained by fasting glucose target or baseline diabetic control. Of the remaining unpooled trials, two showed higher fasting glucose values in the biphasic group (in combined crossover data [38] or without reporting measures of dispersion [41]), one did not quote fasting values [40], one found no difference in fasting measures [43] and two with patients already taking insulin reported a higher percentage of the basal group reaching a target fasting value $[44,45]$.

$P P G$ Nine trials reported PPG measures. Three found a significant reduction in mean PPG for all meals with biphasic insulin $[36,43,44]$ and four showed a reduced PPG rise that was statistically significant for breakfast $(0.8$ vs $2.5 \mathrm{mmol} / 1, p<0.001$ [37], 0.94 vs $2.63 \mathrm{mmol} / 1, p=0.012$ [38], 1.89 vs 3.07, $p<0.01$, [39], $1.26 \mathrm{mmol} / 1$ difference $p<0.0001$ [41]) and evening meals (0.79 vs $2.55 \mathrm{mmol} / \mathrm{l}$, $p<0.001$ [38], 1.06 vs $2.32 \mathrm{mmol} / 1, p<0.05$ [39], $1.33 \mathrm{mmol} / 1$ difference [41]). One reported a greater proportion of biphasic arm patients reaching PPG targets after lunch and supper [45] and one reported no significant difference in PPG values [42].

Weight Pooling four trials [36, 37, 39, 40] showed that, compared with basal insulin, biphasic insulin was associated with a non-significant greater weight increase of $1.29 \mathrm{~kg}(95 \% \mathrm{CI}-0.43,3.03, p=0.15)$ (Fig. 2c). Two trials did not report change in weight [41, 42]. One reported weight loss with basal insulin in non-naive patients [45] and three crossover trials reported reduced weight gain with basal insulin without within-person differences [38, 43, 44].

Hypoglycaemia Pooled analysis was not possible due to variation in definitions of hypoglycaemia and lack of measures of dispersion. Only one trial reported the occurrence of major events (requiring third-party assistance) in either group [45]. Minor hypoglycaemic events were significantly increased for biphasic insulin in five trials $[36,38,39,43,45]$ with no difference reported in the remaining trials.

Prandial vs basal insulin

Seven trials that recruited a total of 1,216 insulin-naive patients with median follow-up of 6 months (range 3-12 months) compared a short-acting prandial insulin with basal insulin.

$H b A_{l c}$ Pooling seven trials $[36,37,46-50]$ showed that, compared with basal insulin, prandial insulin reduced $\mathrm{HbA}_{1 \mathrm{c}}$ by a further $0.45 \%(95 \% \mathrm{CI} 0.16-0.73, p=0.002)$ (Fig. 2d) but with significant variation between the trials $\left(I^{2}=70.6 \%\right)$. Heterogeneity was not explained by use of OHAs, baseline diabetic control, reporting of insulin titration, use of analogue rather than conventional insulin or quality score. Five trials reported final insulin doses and all were greater for prandial insulin.

Fasting glucose Pooling six trials [36, 37, 46-49] showed that, compared with prandial insulin, basal insulin reduced fasting SMBG by a further $2.20 \mathrm{mmol} / 1(95 \%$ CI 1.70-2.70, $p<0.00001$ ) (Fig. 2e) but this varied considerably between studies $\left(I^{2}=44.0 \%\right)$. The SD of change was imputed in one trial [46], assuming a correlation of 0.35 calculated from a trial where data were available [47]. Heterogeneity was not explained by the use of OHAs, fasting targets, baseline diabetic control, titration reporting, use of analogue rather than conventional insulin or quality score.

$P P G$ Five trials reported PPG measures. Three reported greater reductions in PPG after all meals with prandial insulin $[36,47,50]$ and two reported reduced glucose 
excursions with prandial insulin, either after all meals (2.1 vs $0.1 \mathrm{mmol} / 1, p<0.001$ [37]) or after a test meal (10.9 vs $12.2 \mathrm{mmol} / \mathrm{l}, p=0.052[46])$.

Weight Pooling six trials [36, 37, 47-50] showed that, compared with basal insulin, prandial insulin increased weight gain by a further $1.86 \mathrm{~kg}(95 \%$ CI $0.80-2.92$, $p=0.0006$ ) (Fig. 2f) but this varied between studies $\left(I^{2}=85.4 \%\right)$. Heterogeneity was not explained by use of OHAs, use of analogue insulin, baseline diabetic control or reporting of insulin titration. A significant excess increase in BMI was reported for prandial insulin in one study [46].

Hypoglycaemia Pooled analysis was not possible due to variation in definitions of hypoglycaemia and lack of measures of dispersion. Two studies reported significantly increased rates of hypoglycaemia with prandial insulin [36, 47]. Only one study reported the occurrence of major hypoglycaemia requiring third-party assistance but with similar rates in prandial and basal groups [47]. No significant differences were found in frequency of events between prandial and basal insulin in four studies [37, 46, $49,50]$ and a further study did not report data [48] (Table 1).

\section{Basal-bolus vs basal insulin}

Two trials compared a basal-bolus regimen with basal insulin. One recruited 30 patients already using insulin for 3 months [51] and the other recruited 38 insulin-naive patients for 6 months [52].

Outcome measures Both trials showed significantly greater reductions in $\mathrm{HbA}_{1 \mathrm{c}}$ with basal-bolus regimens (betweentreatment difference $0.6 \%, p<0.001$ [51], absolute reduction $1 \%$ vs $0.4 \%, p<0.03$ [52]). Fasting glucose values were not significantly different in the two trials. Basal-bolus insulin reduced PPG after lunch and dinner in one trial [51] and resulted in no change in another [52]. Similar weight gain was reported in one study [52] and rates of hypoglycaemia did not differ significantly.

Biphasic vs prandial insulin

Three trials that recruited 740 insulin-naive patients with median follow-up of 6 months (6-12 months) compared biphasic with prandial insulin $[36,37,53]$.

Outcome measures Pooling three trials showed that biphasic insulin was associated with a non-significant difference in $\mathrm{HbA}_{1 \mathrm{c}}$ reduction of $0.05 \%,(95 \%$ CI $-0.12,0.22$, $p=0.59$ ), although one trial [36] had over $80 \%$ of the weighting of the pooled result, partly due to the much larger sample size. Pooling two trials [36, 37] showed that biphasic insulin was associated with a non-significant further reduction in fasting SMBG of $0.65 \mathrm{mmol} / 1$ (95\% CI $-0.54,1.84, p=0.29)$. Two trials reported postprandial measures: one with a significant reduction in PPG with prandial insulin (-4.6 vs $3.7 \mathrm{mmol} / 1, p<0.001$ [36]) and another with a similar but not statistically significant reduction $(-3.0$ vs $-2.8 \mathrm{mmol} / \mathrm{l}[37])$. Pooling three trials showed that biphasic insulin was associated with a nonsignificantly greater reduction in weight of $0.19 \mathrm{~kg}(95 \%$ CI $-1.16,1.54, p=0.79)$. No major hypoglycaemic events were reported. One trial reported significantly increased minor hypoglycaemia with prandial insulin [36] and one reported a non-significant increase with prandial insulin [37].

Biphasic vs basal-bolus insulin

Four trials recruited 1,061 patients already using insulin with a median follow-up of 4 months (3-6 months). Data presented were not sufficient for meta-analysis.

Outcome measures Two trials compared prandial biphasic $[54,55]$ and one compared twice-daily biphasic [56] with basal-bolus insulin and showed no difference in $\mathrm{HbA}_{1 \mathrm{c}}$ reduction. One trial found greater $\mathrm{HbA}_{1 \mathrm{c}}$ reduction with prandial (and discretionary basal) insulin compared with once- or twice-daily biphasic insulin [57]. Lower fasting glucose and PPG with basal-bolus therapy were found in one trial, which had significantly greater total insulin daily dose in that arm [55]. Three trials reported similar weight gain in both study arms $[54,55,57]$. Similar rates of all hypoglycaemic events were reported in three trials $[54,55,57]$ and two trials reported similar rates of severe hypoglycaemia $[54,55]$.

\section{Other variables}

No trials assessed morbidity and mortality. Patient satisfaction was rarely and inconsistently reported. The dataset was too small to assess publication bias.

\section{Discussion}

Of 22 trials, 15 provided sufficient information for metaanalysis but with considerable variation in titration methodology (where reported), glycaemic targets and definitions of hypoglycaemia. Both biphasic and prandial insulin were 
associated with a greater reduction in $\mathrm{HbA}_{1 \mathrm{c}}$, compared with basal insulin, but this effect was not consistent across pooled trials. Conversely, basal insulin was associated with greater reductions in fasting glucose compared with biphasic and prandial insulin with most trials reporting less improvement in PPG control with basal insulin. Biphasic insulin produced similar outcomes when compared directly with prandial or with basal bolus regimens. The effect of the different insulin regimens on hypoglycaemia event rates could not be pooled in a meta-analysis, which means that a potentially important finding may have been missed given that individual trials were not powered to detect differences in major hypoglycaemic events. Weight gain was only increased significantly with prandial insulin compared with basal insulin.

We calculated effect estimates of insulin regimens by pooling studies where the use or non-use of OHAs was balanced across treatment arms. We also pooled trials using regular and analogue insulin, since a recent meta-analysis suggests that there is no clinically significant difference in efficacy as measured by $\mathrm{HbA}_{1 \mathrm{c}}$ [23]. Examination of the pooled results for heterogeneity did not identify any differences that might arise from the use or non-use of OHAs, or from the use of analogue rather than conventional insulin. In addition, trials on purely insulin-naive patients were analysed separately to estimate relative effects of different regimens at insulin initiation.

Our results should be interpreted with caution given that the majority of trials were of low methodological quality and we were unable to perform full subgroup analyses of heterogeneity for all comparisons. With a larger number of trials, heterogeneity in $\mathrm{HbA}_{1 \mathrm{c}}$ may be more appropriately investigated using meta-regression for continuous baseline variables, e.g. pre-study $\mathrm{HbA}_{1 \mathrm{c}}$, rather than dichotomising variables for subgroup analysis. The forest plots show that heterogeneity was predominantly quantitative rather than qualitative and there may be some inaccuracy in effect size estimates. Heterogeneity remained unexplained for all pooled comparisons and this could be due to small numbers of studies (which limits relevant subgroup comparisons) or inherent variation in insulin titration which was not quantifiable (although suggested by differences in final insulin doses). Titration protocols were sufficiently reported in only a few trials and different glycaemic targets are likely to produce differences in $\mathrm{HbA}_{1 \mathrm{c}}$ reduction.

Critically, the trials were too short to assess vascular event rates or other clinical outcomes; indeed only three trials were $>12$ months. The quality-of-life assessments could not be pooled. Hypoglycaemia was not uniformly defined and event rate data were not reported with measures of dispersion, thus preventing meta-analysis.

Biphasic and prandial insulin regimens may lead to better glycaemic control than basal insulin when used as initial insulin therapy. This is important, as early glucose control may reduce the development of complications [58]. The UKPDS demonstrated that a sustained difference of $0.9 \%$ in $\mathrm{HbA}_{1 \mathrm{c}}$ between conventional and intensive glucose control policies was associated with a relative reduction of $25 \%$ in microvascular complications [3]. The greater mean reductions in $\mathrm{HbA}_{1 \mathrm{c}}$ reported here for both prandial and biphasic insulin of $0.45 \%$, if sustained in the long-term, may well equate to a relative reduction in complications of up to half that seen in the UKPDS. However, we excluded trials with an unbalanced use of OHAs and, given that in routine clinical practice biphasic and prandial insulins are rarely combined long-term with sulfonylureas, we could not assess whether either of these regimens used alone would be superior to basal insulin combined with a sulfonylurea. Furthermore, any improvements seen in $\mathrm{HbA}_{1 \mathrm{c}}$ in these short-term trials may not be sustained over a longer time period. This is particularly important in interpreting comparisons between biphasic and basal insulin where the basal components in one regimen are being administered twice daily and in the other, once daily. Twice-daily dosing allows greater opportunity for dose titration and in the short-term this may result in a greater $\mathrm{HbA}_{1 \mathrm{c}}$ reduction.

Significantly increased weight gain was seen with prandial compared with basal insulin, the greatest difference being when insulin detemir was used as a basal insulin [36]. Although there is some evidence that insulin detemir may result in less weight gain compared with conventional basal insulin [59], this may not be the case for other analogue insulins [60].

It is claimed that patients prefer basal insulin due to its simplicity and the reduced frequency of injections and monitoring [21]. Patient satisfaction assessments have not been sufficiently reported in this review to assess whether this perception of patient preference is true. No trials reported differences in major hypoglycaemic events in the comparisons with basal insulin, but we could not estimate the size of any effect of regimen on minor hypoglycaemic events.

The improvement in $\mathrm{HbA}_{1 \mathrm{c}}$ with prandial and biphasic insulin relative to basal insulin occurred despite poorer control of fasting glucose. However, some authors have argued that fasting values are more significant determinants of glycaemic control $[20,22]$. Furthermore, half the patients in the biphasic trials were poorly controlled and previous evidence has suggested that the contribution of fasting glucose to $\mathrm{HbA}_{1 \mathrm{c}}$ increases at higher values of $\mathrm{HbA}_{1 \mathrm{c}}$ [61].

There is emerging evidence that controlling postprandial glycaemia is important in the reduction of vascular risk. Postprandial glucose was an independent risk factor for 5 year cardiovascular event risk in type 2 diabetes even when $\mathrm{HbA}_{1 \mathrm{c}}$ was included in modelling [62]. The STOPNIDDM trial [63] showed a reduction in cardiovascular events in patients with impaired glucose tolerance given acarbose to reduce postprandial glucose without a signifi- 
cant change in $\mathrm{HbA}_{1 \mathrm{c}}$. The DECODE study [64] showed glucose values after oral loading, and not fasting plasma glucose, to be an independent predictor of cardiovascular mortality.

Our conclusions are limited by the small number of trials, together with variations in definitions and insulin dosing. However, a greater reduction in $\mathrm{HbA}_{1 \mathrm{c}}$ for insulinnaive patients with type 2 diabetes can be achieved with a prandial or biphasic compared with a basal insulin regimen, but at the expense of greater weight gain and an unquantified risk of hypoglycaemia. In order for clinicians and patients to make informed choices about the risk and clinical benefit of different regimens, long-term outcome data are required from rigorously conducted trials that use standardised glycaemic targets, titration protocols and definitions of hypoglycaemia.

Acknowledgements The Department of Primary Health Care, University of Oxford is part of the National Institute of Health School for Primary Care Research. D. S. Lasserson is funded by the NIHR funding scheme.

Conflict of interest R. R. Holman is chief investigator on the Treating to Target in Type Two Diabetes (4T) study and has received research support, fees for advisory board membership and lectures from Novo Nordisk, Eli Lilly and sanofi-aventis. A. J. Farmer is a co-investigator on the 4T study. D. S. Lasserson, P. Glasziou and R. Perera declare that there is no duality of interest associated with this manuscript

\section{References}

1. UK Prospective Diabetes Study Group (1995) UK prospective diabetes study 16. Overview of 6 years' therapy of type II diabetes: a progressive disease. Diabetes 44:1249-1258

2. Wild S, Roglic G, Green A, Sicree R, King H (2004) Global prevalence of diabetes: estimates for the year 2000 and projections for 2030. Diabetes Care 27:1047-1053

3. UK Prospective Diabetes Study (UKPDS) Group (1998) Intensive blood-glucose control with sulphonylureas or insulin compared with conventional treatment and risk of complications in patients with type 2 diabetes (UKPDS 33). Lancet 352:837-853

4. Holman RR, Paul SK, Bethel MA, Matthews DR, Neil HA (2008) 10-year follow-up of intensive glucose control in type 2 diabetes. N Engl J Med 359:1577-1589

5. Patel A, MacMahon S, Chalmers J, ADVANCE Collaborative Group et al (2008) Intensive blood glucose control and vascular outcomes in patients with type 2 diabetes. $\mathrm{N}$ Engl $\mathrm{J}$ Med $358: 2560-2572$

6. Gerstein HC, Miller ME, Byington RP, Action to Control Cardiovascular Risk in Diabetes Study Group et al (2008) Effects of intensive glucose lowering in type 2 diabetes. N Engl J Med 358:2545-2559

7. Duckworth W, Abraira C, Moritz T, VADT Investigators et al (2009) Glucose control and vascular complications in veterans with type 2 diabetes. N Engl J Med 360:129-139

8. Ray KK, Kondapally Seshasai SR, Wijesuriya S et al (2009) Effect of intensive control of glucose on cardiovascular outcomes and death in patients with diabetes mellitus: a meta-analysis of randomised controlled trials. Lancet 373:1765-1772

9. Nathan DM, Buse JB, Davidson MB et al (2006) Medical management of hyperglycemia in type 2 diabetes: a consensus algorithm for the initiation and adjustment of therapy. Diabetes Care 32:193-203

10. Skyler JS, Berganstal R, Bonow RO, American Diabetes Association, American College of Cardiology Foundation, American Heart Association et al (2009) Intensive glycemic control and the prevention of cardiovascular events: implications of the ACCORD, ADVANCE, and VA diabetes trials: a position statement of the American Diabetes Association and a scientific statement of the American College of Cardiology Foundation and the American Heart Association. Circulation 119:351-357

11. Turner RC, Cull CA, Frighi V, Holman RR, UK Prospective Diabetes Study (UKPDS) Group (1999) Glycemic control with diet, sulfonylurea, metformin, or insulin in patients with type 2 diabetes mellitus: progressive requirement for multiple therapies (UKPDS 49). JAMA 28:2005-2012

12. Liebl A (2002) Evaluation of risk factors for development of complications in Type II diabetes in Europe. Diabetologia 45: S23-S28

13. Saydah SH, Fradkin J, Cowie CC (2004) Poor control of risk factors for vascular disease among adults with previously diagnosed diabetes. JAMA 291:335-342

14. Peyrot M, Rubin R, Lauritzen T, on behalf of the international DAWN advisory panel et al (2005) Resistance to insulin therapy among patients and providers. Results of the cross-national Diabetes Attitudes, Wishes, and Needs (DAWN) study. Diabetes Care 28:2673-2679

15. Goudswaard AN, Furlong NJ, Valk GD, Stolk RP, Rutten GEHM (2004) Insulin monotherapy vs combinations of insulin with oral hypoglycaemic agents in patients with type 2 diabetes mellitus. Cochrane Database Syst Rev, Issue 4. Art. No.: CD003418. doi:10.1002/14651858.CD003418.pub2.

16. Janka HU, Plewe G, Riddle MC, Kliebe-Frisch C, Schweitzer MA, Yki-Järvinen H (2005) Comparison of basal insulin added to oral agents vs twice-daily premixed insulin as initial insulin therapy for type 2 diabetes. Diabetes Care 28:254-259

17. Owens DR, Zinman B, Bolli GB (2001) Insulins today and beyond. Lancet 358:739-746

18. Halimi S, Raskin P, Liebl A, Kawamori R, Fulcher G, Yan G (2005) Efficacy of biphasic insulin aspart in patients with type 2 diabetes. Clin Ther 27:S57-S74

19. National Institute for Health and Clinical Excellence (2009) Type 2 diabetes: newer agents for blood glucose control in type 2 diabetes. Available from www.nice.org.uk/CG87ShortGuideline, accessed 22 June 2009

20. Bell D (2004) Type 2 diabetes mellitus: what is the optimal treatment regimen? Am J Med 116:S23-S29

21. Riddle M (2005) Making the transition from oral to insulin therapy. Am J Med 118:S14-S20

22. DeFronzo R (1999) Pharmacologic therapy for type 2 diabetes mellitus. Ann Intern Med 131:281-303

23. Siebenhofer A, Plank J, Berghold A, Narath M, Gfrerer R, Pieber TR (2006) Short-acting insulin analogues vs regular human insulin in patients with diabetes mellitus. Cochrane Database Syst Rev Issue 2. Art. No.: CD003287. doi:10.1002/14651858. CD003287.pub4

24. World Health Organisation (1985) Diabetes mellitus. Report of a WHO Study Group. WHO Technical Report Series 727

25. American Diabetes Association (1997) Report of the expert committee on the diagnosis and classification of diabetes mellitus. Diabetes Care 20:1183-1197 
26. Richter B, Ebrahim SH, Bergerhoff K, Paletta G, Bandeira-Echtler E (2004) Metabolic and Endocrine Disorders Group. About The Cochrane Collaboration (Cochrane Review Groups (CRGs)). The Cochrane Library, Issue 3, Wiley, Chichester

27. Jadad AR, Moore RA, Carroll D et al (1996) Assessing the quality of reports of randomized clinical trials: is blinding necessary? Control Clin Trials 17:1-12

28. Green S, Higgins J (eds) (2005) Cochrane Handbook for Systematic Reviews of Interventions 4.2.5 (updated May 2005). In: The Cochrane Library (Issue 3). Wiley, Chichester

29. Elbourne DR, Altman DG, Higgins JPT, Curtin F, Worthington HV, Vail A (2002) Meta-analyses involving cross-over trial: methodological issues. Int J Epidemiol 31:140-149

30. DerSimonian R, Laird N (1986) Meta-analysis in clinical trials. Control Clin Trials 7:177-188

31. Deeks JJ, Altman DG, Bradburn MJ (2001) Statistical methods for examining heterogeneity and combining results from several studies in meta-analysis. In: Egger M, Davey Smith G, Altman DG (eds) Systematic reviews in health care: meta-analysis in context, 2nd edn. BMJ, London

32. Higgins JP, Thompson SG (2002) Quantifying heterogeneity in a meta-analysis. Stat Med 21:1539-1558

33. Sandercock J, Parmar M, Torri V, Qian W (2002) First-line treatment for advanced ovarian cancer: paclitaxel, platinum and the evidence. Br J Cancer 87:815-824

34. Egger M, Davey Smith G, Schneider M, Minder C (1997) Bias in meta-analysis detected by a simple graphical test. BMJ 315:629-634

35. Moher D, Cook DJ, Eastwood S, Olkin I, Rennie D, Stroup DF (1999) QUOROM Group: improving the quality of reports of meta-analyses of randomized controlled trials: the QUOROM statement: quality of reporting of meta-analyses. Lancet 354:1896-1900

36. Holman R, Thorne K, Farmer A, for the 4-T Study Group et al (2007) Addition of biphasic, prandial, or basal insulin to oral therapy in type 2 diabetes. N Engl J Med 357:1716-1730

37. Kazda C, Hulstrunk H, Helsberg K, Langer F, Forst T, Hanefeld M (2006) Prandial insulin substitution with insulin lispro or insulin lispro mid mixture vs basal therapy with insulin glargine: a randomized controlled trial in patients with type 2 diabetes beginning insulin therapy. J Diabetes Complications 20:145-152

38. Malone J, Kerr L, Campaigne B, Sachson R, Holcombe J, for the Lispro-Mixture-Glargine Study Group (2004) Combined therapy with insulin lispro Mix 75/25 plus metformin or insulin glargine plus metformin: a 16-week, randomized open-label, crossover study in patients with type 2 diabetes beginning insulin therapy. Clin Ther 26:2034-2044

39. Raskin P, Allen E, Hollander P, for the INITIATE Study Group et al (2005) Initiating insulin therapy in type 2 diabetes. A comparison of biphasic and basal insulin analogs. Diabetes Care 28:260-265

40. Stehouwer M, DeVries J, Lumeij J et al (2003) Combined bedtime insulin-daytime sulphonylurea regimen compared with two different daily insulin regimens in type 2 diabetes: effects on $\mathrm{HbA} 1 \mathrm{c}$ and hypoglycaemia rate - a randomised trial. Diabetes Metab Res Rev 19:148-152

41. Christiansen J, Vaz J, Metelko Z, Bogoev M, Dedov I (2003) Twice daily insulin aspart improves postprandial glycaemic control more effectively than twice daily NPH insulin, with low risk of hypoglycaemia, in patients with type 2 diabetes. Diabetes Obes Metab 5:446-454

42. Kilo C, Mezitis N, Jain R, Mersey J, McGill J, Raskin P (2003) Starting patients with type 2 diabetes on insulin therapy using once-daily injections of biphasic insulin aspart 70/30, biphasic human insulin $70 / 30$, or NPH insulin in combination with metformin. J Diabetes Complications 17:307-313
43. Jacober S, Scism-Bacon J, Zagar A, for the IONW Study Investigators (2006) A comparison of intensive mixture therapy with basal insulin therapy in insulin-naïve patients with type 2 diabetes receiving oral antidiabetes agents. Diabetes Obes Metab $8: 448-455$

44. Malone J, Bai S, Campaigne B, Reviriego J, AugendreFerrante B (2005) Twice-daily pre-mixed insulin rather than basal insulin therapy alone results in better overall glycaemic control in patients with Type 2 diabetes. Diabet Med 22:374381

45. Robbins D, Beisswenger P, Ceriello A, for the IOOI Study Investigators et al (2007) Mealtime 50/50 basal + prandial insulin analogue mixture with a basal insulin analogue, both plus metformin, in the achievement of target $\mathrm{HbAlc}$ and pre- and postprandial blood glucose levels in patients with type 2 diabetes: a multinational, 24-week, randomized, open-label, parallel-group comparison. Clin Ther 29:2349-2364

46. Bastyr E, Stuart C, Brodows R, for the IOEZ Study Group et al (2000) Therapy focused on lowering postprandial glucose, not fasting glucose may be superior for lowering $\mathrm{HbA} 1 \mathrm{c}$. Diabetes Care 23:1236-1241

47. Bretzel R, Nuber U, Landgraf W, Owens D, Bradley C, Linn T (2008) Once-daily basal insulin glargine vs thrice-daily prandial insulin lispro in people with type 2 diabetes on oral hypoglycaemic agents (APOLLO): an open randomised controlled trial. Lancet 371:1073-1084

48. Landstet-Hallin L, Adamson U, Arner P, Bolinder J, Lins P-E (1995) Comparison of bedtime NPH or preprandial regular insulin combined with glibenclamide in secondary sulfonylurea failure. Diabetes Care 18:1183-1186

49. Paterson K, Wilson M, Kesson C et al (1991) Comparison of basal and prandial insulin therapy in patients with secondary failure of sulphonylurea therapy. Diabet Med 8:40-43

50. Taylor R, Foster B, Kyne-Grzebalski D, Vanderpump M (1994) Insulin regimens for the non-insulin dependent: impact on diurnal metabolic state and quality of life. Diabet Med 11:551-557

51. Ceriello A, del Prato S, Bue-Valleskey J et al (2007) Premeal insulin lispro plus bedtime NPH or twice-daily NPH in patients with type 2 diabetes: acute postprandial and chronic effects on glycemic control and cardiovascular risk factors. J Diabetes Complications 21:20-27

52. Hendra T, Taylor C (2004) A randomised trial of insulin on wellbeing and carer strain in elderly type 2 diabetic subjects. J Diabetes Complications 18:148-154

53. Hirao K, Arai K, Yamauchi M, Tagaki H, Kobayashi M, for the Japan Diabetes Clinical Data Management Study Group (2008) Six-month multicentric, open-label, randomized trial of twicedaily injections of biphasic insulin aspart 30 vs multiple daily injections of insulin aspart in Japanese type 2 diabetic patients (JDDM 11). Diabetes Res Clin Pract 79:171-176

54. Ligthelm R, Mouritzen U, Lynggaard H et al (2006) Biphasic insulin aspart given thrice daily is as efficacious as a basal-bolus regimen with four daily injections. A randomised open-label parallel group four months comparison in patients with type 2 diabetes. Exp Clin Endocrinol Diabetes 114:511-519

55. Miyashita Y, Nishimura R, Nemoto M et al (2008) Prospective randomized study for optimal insulin therapy in type 2 diabetic patients with secondary failure. Cardiovasc Diabetol 7:16-24

56. Rosenstock J, Ahmann A, Colon G, Scism-Bacon J, Jiang H, Martin S (2008) Advancing insulin therapy in type 2 diabetes previously treated with glargine plus oral agents. Diabetes Care 31:20-25

57. Bretzel R, Arnolds S, Medding J, Linn T (2004) A direct efficacy and safety comparison of insulin aspart, human soluble insulin, and human premix insulin (70/30) in patients with type 2 diabetes. Diabetes Care 27:1023-1027 
58. Bailey CJ, del Prato S, Eddy D, Zinman B, on behalf of the Global Partnership For Effective Diabetes Management (2005) Earlier intervention in type 2 diabetes: the case for achieving early and sustained glycaemic control. Int J Clin Pract 59:1309-1316

59. Dornhorst A, Lüddeke H, Koenen C, PREDICTIVE Study Group et al (2008) Transferring to insulin detemir from NPH insulin or insulin glargine in type 2 diabetes patients on basal-only therapy with oral antidiabetic drugs improves glycaemic control and reduces weight gain and risk of hypoglycaemia: 14-week followup data from PREDICTIVE. Diabetes Obes Metab 10:75-81

60. Bazzano LA, Lee LJ, Shi L, Reynolds K, Jackson JA, Fonseca V (2008) Safety and efficacy of glargine compared with NPH insulin for the treatment of Type 2 diabetes: a meta-analysis of randomized controlled trials. Diabet Med 25:924-932

61. Monnier L, Lapinski H, Colette C (2003) Contributions of fasting and postprandial plasma glucose increments to the overall diurnal hyperglycemia of type 2 diabetic patients. Variations with increasing levels of HbA1c. Diabetes Care 26:881-885

62. Cavalot F, Petrelli A, Traversa M et al (2006) Postprandial blood glucose is a stronger predictor of cardiovascular events than fasting blood glucose in type 2 diabetes mellitus, particularly in women: lessons from the San Luigi Gonzaga Diabetes Study. J Clin Endocrinol Metab 91:813-819

63. Chiasson J-L, Josse R, Gomis R, Hanefeld M, Karasik A, Laakso M (2003) Acarbose treatment and the risk of cardiovascular disease and hypertension in patients with impaired glucose tolerance. The STOP-NIDDM trial. JAMA 290:486-494

64. The DECODE study Group on behalf of the European Diabetes Epidemiology Group (1999) Glucose tolerance and mortality: comparison of WHO and American Diabetes Association diagnostic criteria. Lancet 354:617-621 